\title{
CONCEPÇÕES SOBRE A UTILIZAÇÃO DA LITERATURA INFANTIL NA ESCOLA INTEGRAL ENTRE PROFESSORES DO ENSINO FUNDAMENTAL I
}

\author{
Maryna dos Santos Nascimento ${ }^{1}$ \\ Ludgleydson Fernandes de Araújo ${ }^{2}$
}

\section{RESUMO}

Este artigo buscou compreender as concepções dos docentes sobre a Literatura infantil em uma escola de tempo integral, e ainda como esse gênero literário poderá ser utilizado no espaço escolar para habilitar os alunos a se tornarem bons leitores letrados e emancipados socialmente. Para isso utilizou-se a pesquisa de análises semânticas com educadores do Ensino Fundamental I, onde identificaram que as palavras: aprendizagem, qualidade, disciplina, formação, leitura, estímulo, ludicidade, entre outras, se associam semanticamente e conceitualmente com o tema deste trabalho, ainda percebeu-se que os docentes, compreendem a importância do conhecimento integral na formação do ser humano e que a presença da Literatura infantil na rotina de uma escola de educação em tempo integral contribui de maneira significativa para essa formação objetivada.

Palavras-chave: Literatura infantil. Escola integral. Professores.

1 Graduada em Letras e Especialista em Docência em Escola de Tempo Integral pela Universidade Federal do Piauí - UFPI. E-mail: marypinksantos@hotmail.com.

2 Professor Adjunto do Programa de Pós-graduação em Sociologia e do Departamento de Psicologia da Universidade Federal do Piauí. Doutor em Psicologia pela Universidade de Granada (Espanha), com período sanduíche na Universitá di Bologna (Itália). E-mail: ludgleydson@yahoo.com.br. 


\section{CONCEPTS ON THE USE OF CHILDREN'S LITERATURE IN FULL SCHOOL AMONG TEACHERS OF ELEMENTARY SCHOOL}

\section{ABSTRACT}

This article sought to understand the conceptions of teachers on children's literature in a full-time school, and also how this genre can be used at school to enable students to become good readers literate and socially emancipated. For this we used the research of semantic analysis with educators from elementary school, which found that the words : learning, quality, discipline, training, reading, encouragement, playfulness, among others, are associated semantically and conceptually with the theme of this work it was also realized that teachers, understand the importance of full knowledge in the formation of the human being and that the presence of children's literature in the routine of an education full time school contributes significantly to this objectified training.

Keywords: Children's Literature. Full school. Teachers.

\section{CONCEPCIONES SOBRE LA UTILIZACIÓN DE LA LITERATURA INFANTIL EN LA ESCUELA INTEGRAL ENTRE MAESTROS DE LA ENSEÑANZA FUNDAMENTAL I}

\section{RESUMEN}

En este artículo buscó comprender las concepciones de los docentes sobre la literatura infantil en una escuela de tiempo completo, así como ese género literario será capaz de ser utilizado en el espacio educativo para que los estudiantes puedan convertirse en buenos lectores letrados y emancipados socialmente. Para eso se utilizó la investigación de análisis semánticas con educadores de la Enseñanza Fundamental I, donde se identificaron que las que las palabras: aprendizaje, calidad, disciplina, formación, lectura, estímulo, alegría, entre otros, están 
asociados semánticamente y conceptualmente con el tema de este trabajo, también se dio cuenta de que los maestros, comprenden la importancia del conocimiento completo en la formación del ser humano y que la presencia de la Literatura infantil en la rutina de una escuela de educación de tiempo completo contribuye de manera significativa para esa formación objetivada.

Palabras clave: Literatura infantil. Escuela integral. Maestros.

\section{INTRODUÇÃO}

O filosofo Aristóteles na antiguidade já defendia que a educação escolar contemplasse as diversas áreas do conhecimento e que o ser humano aprendesse de forma contextualizada, relacionando o que foi aprendido em sala de aula com a sua vivência, dessa forma Gadotti (2009), reconhecia o indivíduo como um ser sociável, que está em permanente mudança e que as práticas escolares deveriam promover o interesse pelo conhecimento da diversidade cultural encontradas na sociedade. Fernando de Azevedo, no Manifesto dos Pioneiros, reconhecia a educação integral como um direito biológico do indivíduo, cabendo ao Estado em cooperação com as demais instituições sociais a organização para tornar a escola pública mais acessível a todos os cidadãos, afirmando que:

\footnotetext{
Mas, do direito de cada indivíduo à sua educação integral decorre logicamente para o Estado que o reconhece e proclama, o dever de considerar a educação, na variedade de seus graus e manifestações, como uma função social e eminentemente pública, que ele é chamado a realizar com a cooperação de todas as instituições sociais. (O MANIFESTO..., 1932, p.43).
}

Revelando que todas as práxis pedagógicas nas escolas públicas devem oferecer conhecimentos sem fragmentações, de forma significativa e contextualizada com a realidade que os alunos daquele 
segmento educacional se inserem, assim ele passará a interagir melhor com as práticas sociais que o cercam.

Percebendo que através da leitura pode-se compor, ampliar, organizar e integrar os conhecimentos, a escola poderá utilizar textos atraentes e organizar o ambiente para despertar com constância e regularidade o hábito de ler, para que as crianças ainda nos primeiros anos escolares com o auxílio do professor criem mecanismos de cognição, alfabetização, letramento, entre outros. Paulo Freire em seu livro: $\mathrm{O}$ ato de ler, já alertava para o fato de que "O ato de ler antecede o ato de escrever" (FREIRE, 1989, p.9) indicando que antes da escrita, a leitura de mundo é a primeira interpretação que a criança faz sobre tudo que está a sua volta, pois ainda sem a codificação dos escritos, ela encontra significações em textos não verbais tais como: cartazes, anúncios, rótulos, códigos entre outros.

Desse modo, o espaço escolar é um lugar privilegiado quando as propostas didáticas concedem ao aluno o contato com o maravilhoso mundo da fantasia através dos contos literários, que são funcionais quando afetam positivamente na linguagem, na comunicação, na transformação de informações lidas em conhecimentos práticos e ainda no desenvolvimento da imaginação e da criatividade, inerentes ao ser humano, assim a Literatura infantil, pode ser caracterizada como uma narrativa que descreve e apresenta um mundo imaginário a um público leitor que está em constante descoberta.

E foi a partir dos anos 70 que as instituições escolares perceberam que esse gênero textual incentivou a maioria dos alunos a praticar a leitura diária, com isso os livros infantis passaram a ter espaço reservado na sala de aula, em um momento de interação e encontro entre professor, alunos e mensagem textual, essa união começou a fazer parte da rotina escolar como comenta Silva "A escola, então, redescobriu a literatura, e as editoras descobriram a escola" (SILVA, 2009, p.11). Nos anos 80, a Literatura já estava sendo reconhecida como um componente curricular que auxiliava os professores desde a alfabetização até a formação do cidadão leitor, passando a ser alvo de pesquisa e estudo nas 
Universidades e nos cursos de formação de professores, onde buscavam identificar novos métodos de incentivo à leitura e como torná-la mais produtiva em sala e aula.

Com as novas adequações de tempo e espaço que a escola em tempo integral sugere, faz-se necessário planejar processos interdisciplinares, que busquem adequar as informações encontradas nos livros de Literatura infantil com os conteúdos curriculares seguidos pelo programa escolar, garantindo assim a integralidade do ensino assegurada na Lein ${ }^{\circ}$.9.394/96 que defineas Diretrizes e Bases da Educação desde país, onde destaca no Art. $34^{\circ} . \S 2^{\circ}$. "O ensino fundamental será ministrado progressivamente em tempo integral, a critério dos sistemas de ensino." (BRASIL, 1996). Nesta visão é perceptível que os processos de ensino-aprendizagem devam levar em conta a multiplicidade do mundo no qual os alunos estão inseridos, pois é para a atuação no mesmo que as instituições escolares devem se pautar para construir um currículo que vise à formação integral e autônoma do indivíduo.

Encontram-se, em fase de adaptação em algumas escolas públicas de Ensino Fundamental I, o Programa Mais Educação, que se configura como uma modalidade de jornada ampliada, pois funciona no contraturno escolar com atividades tais como: dança, música, teatro, oficinas, dentre outras, e pode ser compreendida como um ensaio para a implantação de futuras escolas de educação integral em tempo integral, que é um projeto mais amplo e concebido como um espaço onde os alunos passarão o dia inteiro experimentando espaços variados de aprendizagens, ou seja, o horário integral é aquele que as crianças tem aula de matemática e logo em seguida transforma aquelas informações em conhecimentos práticos na aula de xadrez, por exemplo.

Pensar em Educação Integral é pensar na maior permanência dos estudantes na escola, e que isto exige ampliação e organização de tempo e espaço, para serem desenvolvidas diversas atividades que trabalhem os aspectos físicos, sociais, afetivos, cognitivos e linguísticos, além de noções de higiene e valores em um ambiente com instalações adequadas para que os alunos se sintam confortáveis 
garantindo assim sua permanência no ambiente escolar por isso educar integradamente é uma tarefa que os órgãos públicos e os educadores devem executar juntos entendendo e desempenhando suas funções de maneira qualitativa para promover uma educação emancipada integradora e integrada.

\footnotetext{
Trata-se de enfrentarmos esta questão básica: a educação integral melhor se concretiza se, além de a defendermos teoricamente, organizarmos processos e projetos "eco-político-pedagógicos" que nos ajudem a estabelecer prioridades de ação nos orientem sobre as reais necessidades em termos de recursos e condições gerais de infraestrutura para que ela aconteça. (GADOTTI, 2009, p. 11).
}

Esses processos e projetos são reconhecidos como um trabalho de parcerias que vão além dos muros da escola, ou seja, que existam nos currículos das instituições propostas para o desenvolvimento de atividades em diversificados ambientes ao redor da escola, ou seja, em lugares onde os alunos possam se posicionar, assimilando vários contextos sociais tais como: teatros, cinemas, parques, praças, entre outros, como espaços de diferentes oportunidades de aprendizagens. Para se identificar, algumas concepções sobre o trabalho com Literatura infantil na escola de educação em tempo integral, neste estudo utilizouse o método semântico de associações de palavras, que apontará as concepções dos educadores acerca de tal fato.

Como instrumento de pesquisa a construção de lista para coletar as palavras que se associavam entre si, baseadas na palavraestímulo dita pelo pesquisador. Para melhor conceituar e expor os resultados, produziu-se posteriormente duas tabelas que elencaram as palavras obtidas na pesquisa por peso semântico e para apresentar as conclusões deste estudo, procurou-se fazer um diálogo dos resultados encontrados com alguns educadores que estudam sobre essas temáticas. Baseado neste contexto, elegeu-se como objetivo geral deste trabalho, investigar as concepções dos professores do Ensino Fundamental I, acerca da utilização da Literatura infantil, na Escola de 
Educação em Tempo Integral, dessa forma este gênero é caracterizado por Nelly Novaes Coelho (2000) como promotor da nova mentalidade, que vem sendo exigida desde o início do séc. XX.

\section{Percurso Metodológico}

Uma pesquisa científica é uma investigação quando sistematizada e organizada de acordo com as normas estabelecidas cientificamente, para se chegar a um resultado, faz-se necessário a aplicação de um método em um determinado tipo de pesquisa, onde se utilizam alguns instrumentos que servem como coleta de dados para análise e reflexões. Neste trabalho, usou-se a pesquisa qualitativa que segundo Gonsalves (2007), este tipo de busca importa-se mais com a compreensão e a interpretação do fenômeno, refletindo o significado que os outros dão às suas práticas.

O caminho sistematizado para se alcançar os objetivos de uma pesquisa é chamado de Método, Gonsalves (2007) entendido como um estudo investigativo que proporciona ao investigador o contato com o status quo que o objeto se encontra. Escolheu-se utilizar o método de associações semânticas, onde através da combinação das palavras, o participante foi levado a fazer mentalmente uma relação livre e escrever a primeira palavra que ele lembre, e que esta tenha relação semântica, ou significativa quando ele ouvir do pesquisador uma palavra-estímulo como chave para apresentar dados importantes para o estudo.

As palavras estímulos escolhidas para este estudo foram: Literatura Infantil e Escola em educação de tempo integral, que permitiram ao investigador ampliar o campo investigativo. Pois como afirma Ferrarezi (2008, p. 157) “Entretanto, as línguas naturais possuem algumas palavras que, em certos contextos e em certos cenários, podem ser substituídas uma pela outra sem muito prejuízo de sentido desejado". Neste sentido no método desta pesquisa o pesquisador apresenta um primeiro termo que é chamado de palavra-estímulo, que gera outras palavras chamadas de associadas, que se relacionam em mesmo 
contexto, permitindo um comum espaço a ser estudado.

Esta pesquisa foi realizada com professores da Rede pública do Ensino Fundamental I que trabalham em escolas que recebem o Programa Mais Educação, na cidade de Joaquim Pires-PI, Brasil, que tem em média uma população de 13.817 habitantes, sendo que 4.256 residem na zona urbana, e 9.561 na zona rural. Os sujeitos da pesquisa foram escolhidos por convivência onde se formou uma amostra de 26 docentes, com idade média entre 20 a 55 anos, onde $88,4 \%$ eram do sexo feminino e $11,5 \%$ do sexo masculino.

Para responder os nossos questionamentos utilizou-se a TALP (Técnica de Associação Livre de Palavras), onde os participantes registravam as primeiras 5 palavras que vinham a sua mente, quando ouvia as palavras- estímulos que nortearam o trabalho, e ao final do registro dos vocábulos, os professores responderam um questionário sociodemográfico, que permitiu caracterizar melhor os sujeitos da pesquisa.

Para início do procedimento de coleta, foi feito a calibragem do instrumento com as palavras: criança; futebol, após perceber que o participante entendeu como se desenvolveria a técnica, foi dada a seguinte instrução: “Eu direi uma palavra e você terá que anotar as cinco primeiras palavras que vier em sua cabeça. Essas palavras devem ter relação com a que ouviu, pode ser qualquer palavra, desde que não se repitam e nem que seja a mesma que eu disse". Não foi dado limite de tempo para a execução do método, mas pediu-se que a tarefa fosse cumprida no menor tempo possível, ao término do preenchimento das palavras, pediu-se ainda que o professor as numerassem de 1 a 5 , no grau de importância que as palavras representavam para ele.

Para coletar os dados, marcou-se um horário de acordo com a disponibilidade dos docentes, que aceitaram participar do estudo, nos seus locais de trabalho.

Com os dados coletados, inicialmente criou-se uma lista com as palavras que apareceram em primeiro lugar nos livretos, em 
seguida outra lista com as que estavam em segundo lugar e assim sucessivamente.

Logo se obtinha o Núcleo de Rede (NR) que é formado pelas palavras definidoras, que no caso dessa pesquisa obteve-se para o primeiro estímulo "Literatura infantil", 5 listas com 26 palavras cada, e para a segunda "Educação em escola tempo integral", a mesma quantidade de palavras. Após essa listagem, agrupamos as palavras que se assemelhavam, entre si, quanto à repetência, significado, gênero, número e grau. Utilizou-se ainda o site: www.sinonimos.com.br, que nos auxiliou a verificar os agrupamentos dos termos sinônimos.

Elegendo-se aquela palavra que representava todo grupo, calculou-se a partir da regra de três simples o Peso Semântico (PS), que é definida como a unidade de medida encontrada através da soma da ponderação da frequência pela hierarquização assinalada pelos participantes segundo Araújo; Sá; Amaral; Azevedo; Lobo Filho (2016). A partir dessa informação tínhamos que calcular ainda com a mesma regra a Distância Semântica (DSQ) cuja obtenção só é possível a partir das palavras definidoras do NR, atribuindo o valor de $100 \%$ aquela com maior PS, com esta quantia conseguiu-se comparar a distância das demais palavras.

Seguindo os critérios do método, utilizou-se ainda o Microsoft Excel para a criação de tabelas que permitiram uma melhor organização na exposição dos dados encontrados; então, elencouse duas categorias de análises que possibilitaram clareza no diálogo estabelecido entre dos dados encontrados, os estudos bibliográficos e as impressões do pesquisador sobre o fato estudado.

\section{Análise dos dados}

As medidas de média das cinco palavras estão expostas nas tabelas seguintes, onde partindo dos dados obtidos analisar-se-á, conforme o PS (Peso Semântico) que o vocábulo possuiu em relação ao NR 
(Núcleo de Rede), e quando aos DSQ (Distância Semântica Quantitativa). Nesta situação, refletir-se-á sobre os resultados encontrados, a partir dos teóricos que estudam sobre esses temas:

Tabela 1 - Rede semântica do estímulo Educação em Tempo Integral

\begin{tabular}{ccc}
\hline $\begin{array}{c}\text { NR (Núcleo de } \\
\text { Rede) }\end{array}$ & $\begin{array}{c}\text { PS (Peso Semântico) } \\
\text { F }\end{array}$ & $\begin{array}{c}\text { DSQ (Distância } \\
\text { Semântica) } \\
\%\end{array}$ \\
\hline $\begin{array}{c}\text { Aprendizagem } \\
\text { Qualidade }\end{array}$ & 100 & 100 \\
Disciplina & 32 & 53,3 \\
\hline Formação & 21 & 35 \\
\hline Tempo & 12 & 20 \\
\hline
\end{tabular}

Fonte: Próprios autores.

Conforme se verifica, na Tabela 1, o termo "aprendizagem" apresentou peso semântico de $100 \%$, ou seja, esta palavra foi a principal definidora quando se pensava na educação em tempo integral, pois entende-se que a escola é conhecida como um espaço onde se prioriza os processos de ensino-aprendizagem, e com ampliação dos tempos e espaços que obedecem ao formato da escola de tempo integral, é imprescindível que haja possibilidades para que a aprendizagem significativa aconteça, criando ambientes e situações que facilitem o ensino, pois assim o conhecimento se torna mais concreto e amplo, ou seja, sem fragmentações.

Sobre isso Gadotti (2009, p.11) revela que: "À educação integral quer superar o currículo fragmentado, organizado em grades e fundamentado no isolamento das disciplinas que, por conseguinte, isola as pessoas e cria guetos de aprendizagem", desse modo identificase que o ensino da escola de educação de tempo integral, implica diretamente na atuação social dos alunos, pois quando ele é feito de forma prazerosa e significativa, percebe-se a influência positiva na vida dos estudantes, no entanto, quando as práxis de ensino-aprendizagem 
não acontecem de forma qualitativa, o déficit é perceptível percebendo que os estudantes não conseguem usar seus conhecimentos de forma autônoma e acabam isolados da sociedade.

A qualidade do ensino que se oferece nas escolas deve ser fundamental, para que se alcance todos os objetivos da escola integral, que é a atuação do indivíduo nos vários ambientes sociais. Sobre a importância da "qualidade" educacional, que foi definidora com 53, $3 \%$, entende-se que esta vai além do que dar aulas, pois o que importa não é a quantidade de conteúdos que é repassado em sala de aula, mas a qualidade com que eles são transmitidos, e aprendidos pelos alunos, assim afirma Coelho (2009, p.14) que "[...] o problema desses conteudistas não é a falta de conteúdo, mas a pobreza dele "conteúdo". Confirmando assim que a qualidade da educação não se determina pela quantidade de informações dadas em sala de aula, e sim pela aplicação dos conteúdos na vida prática dos alunos, onde eles possam exercer seu papel de cidadão.

Os processos de mecanização, ainda muito frequentes em algumas escolas, ocasionam um ensino baseado na memorização, utilizado apenas para responder as questões das avaliações, mas passado esse período, os alunos não lembram mais do que foi estudado, ou seja, aprenderam mecanicamente, visto que não houve qualidade porque não houve ensino. Vasconcelos faz o seguinte questionamento: "A quem interessa uma educação de qualidade? "(VASCONCELOS, 2006, p.31), pois ele entende a sociedade como uma manipuladora de comportamentos, treinando todos para serem e pensarem iguais. Diante desse contexto é que a escola integrada deve oferecer uma nova concepção de ensino, concedendo ao aluno uma visão ampliada de mundo onde ele possa ser agente crítico e transformador da realidade em que vive.

Com 35\% de distância semântica a palavra "disciplina" encontra-se como uma definidora, da escola de tempo integral o que nos permite interpretar como uma das maiores preocupações dos educadores que trabalham nos programas de jornada ampliada, pois esse novo modelo de educação precisa ser em um ambiente atrativo, 
onde todos os alunos se sintam seduzidos a participar das atividades propostas, Leonel Brizola falava que a educação pública integral não devia se preocupar somente em tirar a criança da rua, mas que desse condições para que a convivência diária fosse produtiva para ela, assim os alunos gostariam mais de estar em sala de aula, evitando muitas vezes a indisciplina.

Sabe-se que é um desafio, manter a disciplina no tempo integral, pois com a presença de um público maior de crianças dentro da escola, o ambiente escolar deve estar organizado e preparado com atividades diversificadas, ou seja, os professores devem planejar diariamente as ações que serão desenvolvidas, fugindo assim dos imprevistos que são muitas vezes causadores o ócio nos estudantes.

Também é importante para a escola que, professores e alunos estabeleçam de forma conjunta algumas regras e limites para a boa convivência de todos, no ambiente escolar, pois a disciplina só poderá ser constituída quando houver organizações das regras, que logo organizam também os limites a serem seguidos e respeitados Freire (2010), percebe-se que um dos fatores mais importantes que podem ajudar a controlar a indisciplina dos alunos que ficam em tempo integral na escola, é o planejamento de docentes e monitores, pois quanto mais houver atividades significativas, lúdicas e prazerosas para este público, o tempo será otimizado oportunizando a construção e produção de conhecimentos.

Para desenvolver essas novas concepções de ensino dentro da escola, entendemos a importância do professor como principal agente formador e transformador nas instituições de ensino, Gadotti (2007, p.62) diz que: "Para melhorar a qualidade da escola, principalmente das escolas públicas, é preciso investir na formação continuada do professor" entendendo assim que os processos formativos docentes ajudam na reflexão sobre as práxis pedagógicas exercidas por eles, ou seja, a formação do professor não se limita à treinamentos eventuais, mas também na avaliação/reflexão que este faz a acerca de seu desempenho dentro de sala de aula. 
Para isso vale ressaltar a importância da "formação" palavra geradora que se associa, com $20 \%$ a escola integral. A pesquisa, o estudo, e a prática são alguns elementos que constituem e formam um professor, pois sua atuação no trabalho é o reflexo dos conhecimentos acumulados que este conquistou durante sua carreira, visto que os melhores resultados oferecem os professores com práticas qualitativas em sala de aula e atualmente é importante que o educador busque novas estratégias de ensino adequadas para a ampliação do tempo escolar.

Para isso o educador deve complementar seus afazeres com novos saberes, segundo Tardif (2010), existem quatro principais campos de conhecimento que ajudam nas práxis do docente, que são os profissionais, disciplinares, curriculares e experiências. O primeiro saber é apresentado ao professor na universidade, onde está em formação inicial ou continuada para aprender técnicas e métodos específicos ao educador, o segundo refere-se às disciplinas humanas encontradas nos currículos dos cursos de licenciatura tais como: antropologia, sociologia, didática, metodologia, entre outras, são essenciais para o conhecimento do público e do ambiente que se irá trabalhar.

O terceiro encontra-se no campo de trabalho, nas instituições escolares, e encontra-se presente na missão social da escola, onde são traçados metas e planos para fazer com que o aluno chegue ao objetivo esperado por aquela instituição, o quarto saber são apreendidos diariamente na prática, no exercício do magistério, onde o professor cria e desenvolve técnicas e habilidades individuais que são aprimoradas ao longo do seu trabalho em sala de aula.

A integralidade permite aos alunos o contato com múltiplas experiências, e para que elas aconteçam de forma satisfatória, faz-se necessário a organização e sistematização do "tempo", palavra que apareceu com $11,6 \%$ de distância semântica das outras, mas que foi notada como uma das principais definidoras quando se pensa na jornada integral, onde ele é compreendido como espaço para se praticar novos comportamentos, pois é necessário tempo para adquirir hábitos 
de leitura ou de higiene pessoal, por exemplo.

A sistematização dos tempos e espaços permitirá, posteriormente, a melhor organização também do corpo discente, pois eles deverão ser levados a compreender através de conversas e acordos que a colaboração deles é necessária para o programa ser melhor desenvolvido, ainda é considerável que o professor entenda que os alunos da jornada integral são heterogêneos e que executam as atividades em momentos diferentes, para isso deve-se considerar que no plano diário do docente existam estratégias diversificadas que façam o aluno continuar aprendendo mesmo em seu tempo livre, assim ele não perderá o interesse em experimentar novas experiências. Para isso o tempo destinado para refletir e planejar deve ser tarefa inseparável de todo professor, pois é a partir desse momento que as teorias ajudam na construção da prática, conforme a seguinte formulação:

Tempo não cai do céu, nem é doado. Tempo é construído e é na construção desse tempo que eu alicerço a minha disciplina intelectual. Se eu tenho aula todo dia, eu organizo meu tempo para escrever, seja uma frase, um parágrafo sobre o que aconteceu na minha aula. Essa reflexão cotidiana já é o embrião da teoria, porque não existe prática sem teoria. (FREIRE, 2010, p.72).

Diante dessas constatações, pode-se entender que um bom planejamento resulta na coerência do trabalho do docente, direcionando-o para alcançar os objetivos propostos, e permitindo que o educador aproveite todo o tempo para desenvolver o processo de ensino e aprendizagem. Considerando o ser humano como um todo, a educação não deve ser fragmentada, pois educar integralmente envolve muitas práticas que precisam se complementar a fim de promover a qualidade da educação, formando um aluno com múltiplos conhecimentos, aberto a novas aprendizagens, que sabe pensar com autonomia e é capaz de transformar informações em conhecimentos práticos necessários aos dias atuais. 
Tabela 2 - Rede semântica do estímulo Literatura Infantil

\begin{tabular}{|c|c|c|}
\hline NR (Núcleo da Rede) & $\begin{array}{c}\text { PS (Peso Semântico) } \\
\text { F }\end{array}$ & $\begin{array}{c}\text { DSQ (Distância } \\
\text { Semântica) } \\
\%\end{array}$ \\
\hline Leitura & 100 & 100 \\
\hline Aprendizagem & 32 & 87,6 \\
\hline Estímulo & 18 & 21,1 \\
\hline Ludicidade & 14 & 16,4 \\
\hline Socialização & 06 & 07 \\
\hline
\end{tabular}

Fonte: Próprios autores.

Considerando a Literatura infantil como uma ferramenta de significações, prazeres e descobertas, a tabela acima mostra que a palavra "leitura" foi utilizada como o termo definidor para tal gênero, com 100\% de distância semântica de todo núcleo de rede, percebendo que na visão dos professores pesquisados o ato de ler funciona como um objeto de conhecimentos. Definida também pelo dicionário Aurélio, essa se conceitua como um ato, ou uma arte que, através de prática constante, traz ao leitor significações e construções a partir do que foi lido.

Paulo Freire (1986), identificava a leitura nas suas 3 formas, onde a primeira chamada de "leitura mecânica" objetivava apenas a decodificação das letras escritas, que funcionavam com um código a ser decifrado, a segunda forma foi chamada de "leitura de mundo" que se caracteriza pelo ato de dar significações a tudo que está em nossa volta, ou seja, são as compreensões provavelmente aprendidas através da vivência. A terceira intitulada de "leitura crítica" é quando o leitor, através da prática, compreende as intenções por traz dos escritos e consegue tomar um posicionamento sobre o texto lido.

E quando pensamos em leitura dentro do ambiente escolar, é necessário que essa seja vista como ferramenta para o conhecimento, pois como afirma Coelho (2000, p.15) “É ao livro, à palavra escrita, que atribuímos a maior responsabilidade na formação da consciência de 
mundo das crianças e dos jovens". Neste contexto observamos que através da leitura o mundo se torna mais perceptível e compreensível, pois não podemos viver em sociedade sem entender as práticas que se organizam nela, tampouco ser passivos a elas, visto que o sujeito leitor é aquele que cria e modica normas sociais.

Compreendendo as leituras como fonte de descoberta, é necessário que a escola organize atividades para promoção de leituras, e levando em conta que os alunos do Ensino Fundamental estão em fase de descoberta, é necessário que os livros escolhidos para o trabalho com esse público sejam atrativos e instigantes, que despertem neles a vontade de ler para descobrir mais, nesse sentindo reconhecemos que a Literatura infantil pode ser apresentada nos primeiros anos escolares como início do trajeto na vida do leitor, pois ela através de sua linguagem acessível consegue transmitir a mensagem de forma simples e prazerosa; assim, as crianças conseguem desenvolver a cognição e consequentemente o aprendizado.

Nesta pesquisa, pela segunda vez a palavra "aprendizagem" foi definidora com $87,6 \%$ da rede semântica de estímulo de Literatura Infantil, essa associação é entendida quando pensamos nas habilidades que esse gênero desperta em seus leitores, principalmente nas crianças. Nesse sentido o Sociólogo francês Soriano (1975 apud COELHO, 2000), compreende a infância como um período de aprendizagens, onde todo e qualquer ensinamento que se dirige a ela, deve ter, necessariamente, uma vocação pedagógica, pois a literatura infantil é também obrigatoriamente pedagógica, visto que toda leitura é intencional ao proporcionar que o leitor descubra novas informações.

Na escola, podemos identificar o professor como promotor da leitura, pois ainda nos anos iniciais se torna o principal meio de comunicação entre os alunos e as historinhas, esse processo de interação entre leitor e ouvinte, pode ser momento de aprendizagem quando é permitido que as crianças sejam ativas naquela narrativa, ou seja, que elas possam apresentar suas inferências, impressões e opiniões sobre o texto. 
Quando os alunos já têm pleno domínio da leitura o papel do professor muda, passando de leitor para mediador, ou seja, deve guiar os estudantes enquanto leitores a estabelecer um diálogo com o texto procurando compreender as informações necessárias para a aprendizagem. E esse é um dos grandes desafios dos educadores atualmente Solé (1998), pois a sociedade exige que o ser humano além de alfabetizado possa ser letrado para agir com autonomia, diante as novas práticas sociais.

Nesse cenário de construção do leitor notamos que a Literatura infantil tem papel fundamental na aquisição da leitura, pois a criança pode facilmente mergulhar no imaginário que o gênero textual permite, e considera-se que a leitura correta é aquela em que o leitor se relaciona com a história, essa relação lúdica que a Literatura especializada para crianças oferece, facilita o encontro prazeroso entre leitor e livro.

Podemos observar na tabela que as palavras "estímulo" e "ludicidade", onde a primeira aparece com $21,1 \%$ e a segunda com $16,4 \%$, esses vocábulos se associam entre si, dado que são práticas que se complementam e não se dissociam, ganham espaço quando são reconhecidas como metodologias que facilitadoras do processo ensinoaprendizagem para o público infantil, ou seja, para que as crianças que estão começando a ter contato com conhecimentos mais formais não sejam desestimuladas, são necessárias atividades que façam parte do universo delas, e a ludicidade é um estímulo que pode aproximar os alunos da literatura, para isso as leituras em sala de aula, não deve ser presas, destinadas somente aos livros didáticos.

Para despertar o hábito de leitura nas crianças, e necessário que a escola procure estratégias para a formação do novo leitor através de projetos de leituras, com atividades significativas e contextualizadas; oficinas de produções que explorem a criatividade dos alunos; cantinhos de leitura em um ambiente atrativo e colorido para as crianças, dentre outros. Sobre isso Rangel fala que: "Defendo a ideia de Paulo Freire de que a leitura deve estar relacionada à realidade do aluno, considerando 
temas significativos, para que haja a possibilidade de o leitor estabelecer constatações e daí. Fazer propostas e construir outros significados" (RANGEL, 2006, p.291).

Percebemos que as leituras literárias, contribuem para que os alunos façam comprovações e se reconheçam como construtores de sua própria formação, assim o ato de ler quando significativo proporciona ao leitor uma efetiva aprendizagem e um melhor entendimento das práticas letradas.

A escola tem atualmente um papel fundamental na formação de leitores literários, e não é só decodificando as palavras que os alunos leem; a qualidade da leitura está quando o educando consegue estabelecer relações entre o que lê e o que pratica, assim a Literatura infantil destina sua composição para que a linguagem e os temas sejam relacionados ao universo infantil, com mensagens que ajudarão as crianças a decifrarem aos poucos das situações no mundo que as cercam.

As oficinas de produções textuais que exploram a criatividade dos alunos; os cantinhos de leitura como ambientes atrativos e coloridos, a contação de historinhas, são atividades que promovem e estimulam os alunos, deve-se também oportunizar espaços para que as crianças, contem sobre suas vivências cotidianas, diante disso o aluno se sente também parte de uma história.

Neste contexto, percebemos que o estímulo para leitura deve começar de um adulto leitor praticante que desde cedo ler contos infantis para seus filhos antes de dormir, logo essa rotina diária de leitura se transforma em curiosidade, despertando na criança a vontade de se apropriar também daquele ato, Pinto (2005, p. 328) comenta que: “[...] a criança vai gostar de ser se o professor ou os pais começarem a ler livros junto com ela. A leitura compartilhada é o segredo", já o professor / monitor da escola de tempo integral, deve fazer com que o aluno sinta vontade de ler criando nele o habito diário para o contato com os livros, mostrando para os alunos outros livros e novas histórias, fazendo 
leitura compartilhada, usando figuras, objetos, gestos, movimentos, onomatopeias, e outros recursos que serviram para aproximá-los daquela interpretação.

A escola em tempo integral pode desenvolver aprendizagens através da literatura, onde a criança perceba que o livro não é só um objeto de papel, mas um instrumento de socialização que Ihe apresentará um maravilhoso mundo de conhecimentos, assim a escola pode auxiliar essa formação do ser humano, com atividades que promovam também a "socialização" palavra definidora que apareceu com $07 \%$ nesta pesquisa, Rangel expõe algumas atividades com leitura que contribuam para socializar os alunos através dos momentos de leitura, tais como:

\footnotetext{
O partilhar a leitura com os colegas da sala, que pode ser concretizado na hora do troca-troca, a organização de uma biblioteca em sala, projeção de filmes e vídeos, contação de causos e histórias, a leitura e criação de histórias as próprias crianças, visitas e consultas às bibliotecas do bairro, etc. (RANGEL, 2006, p.294).
}

Essas atividades aproximam os alunos uns dos outros, também propiciam espaços de troca de conhecimentos onde os alunos podem interagir entre si, nota-se também que a afetividade estabelecida entre professores e alunos é fundamental para estimular o aluno a gostar de determinada atividade em sala de aula, sobre isso Vasconcelos comenta que: "A questão da afetividade é o primeiro elemento para a aprendizagem. O ponto de partida do processo de conhecimento é a mobilização"(VASCONCELOS, 2006, p. 31).Todo educador deve mobilizar, conquistar e envolver seus alunos, para que eles se sintam interessados e motivados para estarem sempre aprendendo, assim a busca pelo conhecimento se torna uma constante meta que eles levaram para a vida toda.

Nota-se que através da utilização da Literatura na escola integral o ser humano é levado a desenvolver todos os aspectos cognitivos, onde é conduzido a se tornar um cidadão que sabe fazer e 
conviver, para isso as atividades realizadas em sala de aula devem sempre objetivar a promoção da leitura, pois através dela é que o homem se formará mais consciente e capaz de transformar a sociedade na qual se insere.

\section{Considerações finais}

A Literatura infantil na escola integral é um desafio para os atuais educadores, pois é necessário promover, através das práticas pedagógicas, o contato interativo entre livro e leitor visando à formação do sujeito letrado e emancipado com habilidades de refletir, meditar e de reconhecer a si mesmo como construtor de sua própria história.

No contexto sociocultural, alvo desta investigação, denota-se que os educadores concebem essa urgência em educar o ser humano de forma integral, pois de acordo com os resultados expostos nas tabelas, as palavras encontradas abrem reflexões importantes para o desenvolvimento do leitor através da jornada integral. Deste modo, entendemos que as práticas escolares bem planejadas, contribuem para uma aprendizagem significativa e prazerosa proporcionando ao aluno múltiplas aprendizagens que despertam nele habilidades e competências necessárias para construção de um ser ativo socialmente.

Considera-se que esta investigação pode contribuir como uma pequena meditação e incentivo para novas pesquisas em busca de estratégias eficazes para os processos formativos do ser humano, pois as análises das concepções docentes mostraram que é importante levar esse gênero textual para a sala de aula, afim de despertar nos alunos o hábito da leitura, tornando-os letrados e autônomos na busca de conhecimentos, capazes de trilhar diferentes caminhos daqueles que suas realidades pré-estabeleciam.

Vale lembrar que este trabalho não é um produto final, pois estudamos uma pequena população de educadores, e sabe-se que ainda há muito que se revelar sobre a função que este novo modelo educacional unido ao gênero textual tem a contribuir para o contexto sócio-histórico-cultural deste país. 


\section{Referências}

ARAÚJO, Ludgleydson Fernandes et al. Escola Arquipélago Fernando de Noronha, Arquipélago Fernando de Noronha, Brasil. Psicologia \& Sociedade, v. 24, n. 1, p. 104-111, 2012.

BRASIL. Lei de Diretrizes e Bases da Educação: Lei no 9.394, de 20 de dezembro de 1996.1996. Disponível em: <portal.mec.gov.br/ componente/article?id=12907>. Acesso em: 13 abr. 2016.

COELHO, Lígia Martha C. da costa (Org.). Educação integral em tempo integral: estudos e experiências em processos. Rio de Janeiro: FAPERJ, 2009.

COELHO, Nelly Novais. Literatura Infantil: teoria, analise, didática. São Paulo: Moderna, 2000.

FERRAREZI, Junior Celso. Semântica para a educação básica. São Paulo: Parábola Editorial, 2008.

FREIRE, Madalena. Políticas Pedagógicas. Revista Direcional Educador, São Paulo, Exclusiva Publicações, 2010.

FREIRE, Paulo. Pedagogia do Oprimido. 17. ed. Rio de Janeiro: Paz e Terra, 1986.

A importância do ato de ler: em três artigos que se completam. São Paulo: Autores Associados: Cortez, 1989.

GADOTTI, Moacyr. Educação Integral no Brasil: inovações em processo. São Paulo. Editora e livraria Instituto Paulo Freire, 2009.

. Políticas Pedagógicas. Revista Direcional Educador, São Paulo, Exclusiva Publicações, 2007.

GONSALVES, Eliza Pereira. Conversas sobre iniciação à pesquisa científica. 4. ed. Campinas, SP: Alínea, 2007.

O MANIFESTO dos pioneiros da educação nova. 1932. Revista HISTEDBR 
On-line, Campinas, n. especial, p.188-204, ago. 2006.

PINTO, Ziraldo Alves. Políticas Pedagógicas. Revista Direcional Educador, São Paulo, Exclusiva Publicações, 2005.

RANGEL, Jurema Nogueira Mendes. Políticas Pedagógicas. Revista Direcional Educador, São Paulo, Exclusiva Publicações, 2006.

SILVA, Vera Maria Tietzmann. Literatura infantil brasileira: um guia para professores e promotores de leitura. 2. ed. Goiânia: [s.n.], 2009.

SOLÉ, Isabel. Estratégias de leitura. 6. ed. Porto Alegre-RS: Artmed, 1998.

TARDIF, Maurice. Saberes docentes e formação profissional. 10. ed. [S.I.]: Vozes. 2010.

VASCONCELOS, Celso. Políticas Pedagógicas. Revista Direcional Educador, São Paulo, Exclusiva Publicações, 2006. 